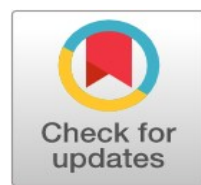

PRIMARY RESEARCH

\title{
Investigating consumer preferences in selecting buffet restaurants in Davao region, Philippines
}

\author{
Dunhill Z. Bilog * \\ Accountancy \& Business Administration Program \\ University of the Immaculate Conception, Bonifacio Street, Davao, Philippines
}

\author{
Keywords \\ Consumer preferences \\ Buffet restaurant \\ Conjoint analysis \\ Two-step cluster analysis \\ Davao region
}

Received: 29 September 2017

Accepted: 2 October 2017

Published: 9 October 2017

\begin{abstract}
The buffet restaurant industry players in Davao region of the Philippines have contributed to economic growth. However, with the influx of national buffet restaurants, the need to revisit the focus of the homegrown buffet restaurant owners and managers has become apparent. Along this is the need to look into the preferences of the buffet restaurant consumers and the segments that patronize the industry. This study primarily sought to identify the attributes consumers in Davao region would look for in a buffet restaurant. It employed an experimental research design where conjoint analysis as a technique was used. Buffet restaurant profiles were generated based on the attributes of types of food, quality of food, price, and cleanliness. These were rated by the respondents. For uncovering the segments, a two-step cluster analysis was utilized. The results of the study indicate that buffet restaurant consumers in the region placed the highest utility on cleanliness. Both junior and senior professionals have the same order of priority as regards the four buffet restaurant attributes. However, the utility values differ. Moreover, three consumer groups, namely single junior professional oriental food lovers, married junior professional oriental food lovers, and married senior professional oriental food lovers were uncovered. These results could prove helpful to buffet restaurant owners and managers in coming up with sustainable service designs and appropriate positioning strategies.
\end{abstract}

(c) 2017 The Author(s). Published by TAF Publishing.

\section{INTRODUCTION}

One of the most highly-competitive industries in the market today is food service. Being so, it is of utmost importance that food service operators take the time to understand their market consumers better considering that it is also the global market's fastest growing industry (Gu \& Kim, 2002). Notably, its players have described their experience as being in the eye of a perfect storm (Haas, 2008). Equally important to note is that the food service industry is continuously impacted by the swift-evolving preferences of the consumer (Waldfogel, 2008). In the US where the restaurant industry is considered a powerhouse, sales volume was projected at 683.4 billion USD, a 3.6 percent increase from 2013 (Riehle, Grindy \& Stensson, 2014). Hence, given these seemingly increasing consumer demand and an increasing difficulty in satisfying restaurant consumers (Han, 2009; Intan, 2016), a thorough analysis to look into ways that would expand consumer base and consequently tap into new opportunities in the market becomes essential (International Markeys Bureau, 2010).

According to Bartlett \& Han (2007), the expectations and evaluations of a consumer will have an influence on the restaurant dining experience. This could well be the reason why today's dining consumers are more impatient (Saputra \& Dewi, 2016; Soderlund \& Ohman, 2005). Due to high expectations coupled with many choices in all these

\footnotetext{
*Corresponding author: Dunhill Z. Bilog

${ }^{\dagger}$ Email: dunhilljigz@gmail.com
} 
restaurant segments, a consumer leaving for another establishment is a common sight (Kang, Nobuyuki \& Herbert, 2004).

According to HRI Food Service Sector (2015), the Philippines has experienced a spike in the growth of its food service industry. This was driven by the increasing number of hotels and shopping malls as well as the arrival of restaurants that are of foreign origin. With these developments in the country and as food service players continue to mushroom, the playing field will become much more competitive (Akbar \& Alaudeen, 2012).

Olsen (2002) asserted that there are other significant factors that traditional restaurants should focus apart from food quality and taste. These are location, atmosphere, serving, tangibles, and interior decorations. Akinyele (2010) supported this with a claim that the restaurant experience would include more than what the customer wants to eat. Hence, for food service industry players, it is not enough anymore to only offer good food and service to attract and retain consumers (Soriano, 2002, Kuo \& Chen, 2015).

In Davao region, a consistently growing economic picture through the years has become apparent. The services sector where food service belongs to recorded a $4.95 \%$ average annual growth rate. Along with this, the sector contributed immensely to the region's economy followed by the industry sector (Regional Development Council Region XI, 2011). Considerably, the food service industry players in Davao City, particularly home-grown buffet restaurants, brought much help.

With this growth in the region comes the influx of national buffet restaurant brands. With these operating in the city, the local buffet restaurant consumers may have altered their view on the homegrown buffet restaurant. Hence, the researcher believes that there could exist a gap between the local buffet restaurant attributes that are being concentrated on by the owners and the consumer preferences for selecting buffet restaurants. The local buffet industry owners might be using their perception in offering buffet restaurant service vis-à-vis the national buffet restaurants. In this light, the researcher proposes this study to narrow the said gap and to provide a significant contribution to the body of knowledge regarding buffet restaurants and their management.

\section{Theoretical Framework}

This study was anchored primarily on consumer behavior theory which has two schools of thought: the cognitive and behavioralist paradigms. Using the cognitive view, the Theory of Reasoned Action is the primary basis of this study. It espoused that personal beliefs towards the attributes of a good or service become the basis for consumer attitude (Ajzen \& Fishbein, 1980). The behavioralist view of the consumer behavior theory could be clearly indicated by the Behavioral Perspective Modeling which emphasized that purchasing behavior is influenced by reinforcing and punishing consequences. These consequences of human behavior are driven by physical and social environment (Foxall, 2010). Another interestingly essential theory central to the direction of this study was the theory of choice. This highlights the normative and descriptive aspects that are taken into consideration when an individual makes a decision. The consumer's beliefs and the individuals' collective description of beliefs and values would come into the picture when making a sequential decision-making (Slovic, Fischhoff, \& Lichtenstein, 1977).

Lastly, the market segmentation theory was adapted. According to Dilworth (2000), a necessary part of achieving quality is understanding who the customers are and what their needs and expectations are. Further, Kotler (2013) mentioned that preferences could be classified as homogeneous, diffused, or clustered.

\section{Conceptual Framework}

The result of the Focus Group Discussion provided the following: the independent variables, which are the attributes of buffet restaurants, and the dependent variable, which is the customer preferences towards selecting a buffet restaurant. Hence, the different attributes of the buffet restaurant, which constitute the independent variables in the study, were type of food, quality of food, price, and cleanliness. These are thought to affect the dependent variable of the study which is the preferences of diners indicated by the total utility they give for a buffet restaurant. The types of food were sub-classified into Filipino, Korean, Japanese, Chinese, European, and American. The quality of food was divided into three levels: excellent, average, and poor. The price levels were above P500, P300-P500, and below P300. Lastly, cleanliness was classified into excellent, average, and poor. 

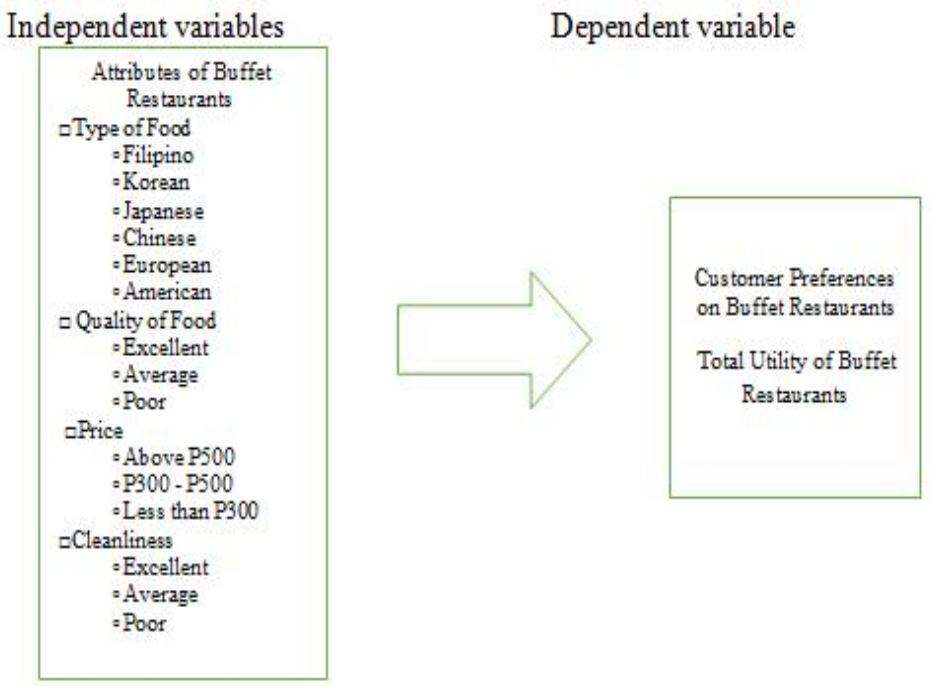

FIGURE 1. Conceptual framework
Dependent variable

\section{Statement of the Problem}

This study aimed to identify the attributes that would comprise the preference structure of consumers for a local buffet restaurant in Davao City.

Specifically, it sought to answer these questions:

1. What attributes of buffet restaurants form the preference structure of consumers classified as junior professionals and senior professionals?

2. What are the utility values that junior professionals attach to the different attributes forming the preference structure for a buffet restaurant?

3. What are the utility values that senior professionals attach to the different attributes forming the preference structure for a buffet restaurant?

4. What is the relative importance of each attribute forming the preferred buffet restaurant of junior professionals? 5 . What is the relative importance of each attribute forming the preferred buffet restaurant of senior professionals?

6. Are there other segments of buffet restaurant consumers with significantly different preferences? What are the distinguishing characteristics of the local buffet restaurants if they significantly exist?

\section{METHODOLOGY}

This study utilized an experimental research design since it employed conjoint experiments (orthogonal design). According to Hair, Black, Babin, \& Anderson (2014), an experimental design used in analyzing consumer preferences has the objective of determining the predictor variables' contribution and forming a valid consumer judgments model.
This is helpful in predicting consumer acceptance towards combinations of attributes. Cochran's (1963) sampling formula was used in generating the minimum sample size. With these results, the study covered 500 buffet restaurant patrons in Davao City. This fell within the median range of 300-550 according to Cattin \& Wittink (1982), which were adapted in the conjoint studies of (Cruz, 1997, 2004; Patayon, 2008). Orme (2010) defined that conjoint-related studies should generally have sample sizes from 150 to 1,200. Further, a probabilistic sampling method employing the concept of Poisson distribution for the total sample size of 500 buffet restaurant patrons was used.

A survey questionnaire was adopted as the method of data collection which was administered in two stages. The first stage involved the Focus Group Discussion wherein the survey questionnaire was given to participants to extract the relevant buffet restaurant attributes consumers would consider important. Subsequently, once important attributes were known, another survey questionnaire was given geared towards the evaluation of 34 buffet restaurant profiles through rating, seven of which were hold-out stimuli.

The data gathered for this study were summarized, interpreted, and analyzed using frequency counts and percentages which described the buffet restaurant consumers' response to the survey items, conjoint analysis to determine the utility of attribute which represents the value consumers put on an attribute level and the importance of attribute, which is simply the difference between the lowest and highest utilities across the levels of attributes 
and two-step cluster analysis used to group objects based on the characteristics they possess so that each object is very similar to others in the cluster with respect to some predetermined selection criterion, in this case, segments.

\section{RESULTS AND DISCUSSION}

\section{Profile of Buffet Restaurant Consumers in Davao Region} As presented in Table 1, around 80.4 percent of the 500 respondents came from Davao del Sur and 2.0 percent were from Compostela Valley. 31.2 percent were 18-25 years old while 2.4 percent were above 60 years old. The College degree holders comprised 78.2 percent whereas Doctorate degree holders registered 1.0 percent. Further, 50.6 percent were male and 40.4 percent were female. Moreover, 51.8 percent were single while only .6 percent were divorced. Lastly, of the 500 respondents, 73.6 percent were Junior professionals.

TABLE 1 . Distribution of buffet restaurant consumers according to demographics

\begin{tabular}{|c|c|c|c|}
\hline & Category & Frequency & Percentage \\
\hline & Davao del Sur & 402 & 80.4 \\
\hline \multirow[t]{4}{*}{ Address } & Davao del Norte & 68 & 13.6 \\
\hline & Davao Occidental & 2 & .4 \\
\hline & Davao Oriental & 18 & 3.6 \\
\hline & Compostela Valley & 10 & 2.0 \\
\hline \multirow[t]{6}{*}{ Age } & $18-25$ & 156 & 31.2 \\
\hline & $26-30$ & 103 & 20.6 \\
\hline & $31-40$ & 120 & 24.0 \\
\hline & $41-50$ & 79 & 15.8 \\
\hline & $51-60$ & 30 & 6.0 \\
\hline & Above 60 & 12 & 2.4 \\
\hline \multirow{5}{*}{ Education } & High School & 58 & 11.6 \\
\hline & College & 391 & 78.2 \\
\hline & Masteral & 36 & 7.2 \\
\hline & Doctorate & 5 & 1.0 \\
\hline & Others & 10 & 2.0 \\
\hline \multirow[t]{2}{*}{ Sex } & Male & 253 & 50.6 \\
\hline & Female & 247 & 40.4 \\
\hline \multirow[t]{4}{*}{ Civil Status } & Single & 259 & 51.8 \\
\hline & Married & 228 & 45.6 \\
\hline & Widowed & 10 & 2.0 \\
\hline & Divorced & 3 & 6 \\
\hline \multirow[t]{4}{*}{ Current Position } & Junior Professional (25-45) & 292 & 73.6 \\
\hline & Senior Professional (above 45) & 105 & 26.4 \\
\hline & Does not belong & 103 & \\
\hline & Total & 500 & 100.0 \\
\hline
\end{tabular}

Utility Values of Buffet Restaurant Attributes by Buffet Restaurant Consumers from the Selected Provinces in Davao Region

As seen in Table 2, all utility values are highly significant. Hence, all the buffet restaurant attributes are looked upon as the basis for the selection of a buffet restaurant. The Pearson's $R$ and Kendall's tau correlations both showed significance at .01 level which means that this model represents the buffet restaurant attributes identified by the respondents. The correlation for holdouts indicates the model is fit, at .05 level of significance.

TABLE 2 . Overall conjoint correlationsresults between observed and estimated preferences of buffet restaurant consumers based on location

\begin{tabular}{lcl}
\hline \hline Correlations & Value & Sig. \\
\hline Pearson's $R$ & .984 & $.000^{* *}$ \\
Kendall's tau & .954 & $.000^{* *}$ \\
Kendall's tau for Holdouts & .905 & $.002^{*}$ \\
\hline \hline Correlations between observed and estimated \\
preferences \\
* Significant at 0.05 level of significance. \\
**.Significant at 0.01 level of significance.
\end{tabular}

As shown in Table 3, Cleanliness earned the highest utility value (35.765). This is in consonance with the studies done by Fatimah, Boo, Sambasivan, \& Salleh (2011), wherein they asserted the importance of food service hygiene or cleanliness.

Further, this aspect remains far more essential since the associated risk could be really substantial. The lowest utility value was registered by Price (8.427) attribute. This means that buffet restaurant consumers no longer consider price as the primary attribute to look into in selecting a buffet restaurant. Instead, they place the highest value on the cleanliness of a buffet restaurant. Chung \& Kim (2011) clarified that price remains one of the major factors that is used in consumer decision-making as well as its subsequent behaviors. Kafel \& Sikora (2013) deepened the insight by asserting that consumers utilize price as a gauge for the quality of the restaurant. Hence, if a restaurant serves quality food, then it must be expensive.

TABLE 3 . Respondents' overall average importance values on the buffet restaurant attributes based on location

\begin{tabular}{ll}
\hline \hline Buffet Restaurant Attributes & Value \\
\hline Type of Food & 25.541 \\
Quality of Food & 30.267 \\
Price & 8.427 \\
Cleanliness & 35.765 \\
\hline \hline Correlations between observed and estimated \\
preferences \\
* Significant at 0.05 level of significance. \\
**.Significant at 0.01 level of significance.
\end{tabular}


Partial utility estimates (or part-worths) can be used to compute the overall utility for each of the four buffet restaurant attributes. This is done as part-worth utility estimates are naturally converted into a common scale. Generally, these estimated utilities are scaled in such a way that they total to zero.

Consequently, a negative number will not mean that a particular level has "negative utility". It just means that the factor level is on average less preferred than a factor level having positive estimated utility (Chapman, 2013). As presented in Table 4, the utility estimates showed a greater preference for Japanese (.042), American (.195), and Filipino (.236) foods. Greater preference is evident as well for average (.139) to excellent (.406) quality of food. As regards the price, preference is less than P300. All of the buffet restaurant attributes are even enhanced if the buffet restaurant sports average (.168) and excellent (.469) cleanliness. As presented, the Korean $(-.221)$, Chinese $(-.040)$, and European (-.212) types of food earned negative utility estimates. Temblor (2016) emphasized that the hesitation about Korean food stemmed from the uniqueness of its taste. However, tremendous appreciation is seen gradually given the noticeable proliferation of Korean culture in the Philippines. Kimchi and Ramyeon are popular Korean dishes that have become household names which are all the more reinforced by Koreans coming to the country to study or do business.

Also, the Chinese food earning a negative utility estimate could have come from the indigenization and transformation of the Chinese food in the country. Fernandez (2002) stressed that while there are a lot of foods that are of Chinese origin, a Filipino consumer would not be able to find a Chinese dish done exactly the way they are in China, or tasting the same. This indigenizing process eventually Filipinized Chinese foods.

Lastly, the European food, according to Roman \& Russell (2009), has always had their influence in Southeast Asia. The love for food such as pan de sal, empanada, kilawin, paella, and a variety of other seasoned meat dishes cannot be denied. However, these, as time went on, experienced indigenization. Hence, most of us perceived them as typical Filipino foods.

TABLE 4 . Respondents' overall utility estimates of factors based on buffet restaurant attributes

\begin{tabular}{llll}
\hline \hline Attribute & Factor & Utility-Estimate (Part-worths) & Std. Error \\
\hline Type of Food & Filipino & .236 & .060 \\
& Korean & -.221 & .060 \\
& Japanese & .042 & .060 \\
& Chinese & -.040 & .078 \\
& European & -.212 & .078 \\
& American & .195 & .078 \\
Quality of Food & Excellent & .406 & .042 \\
& Average & .139 & .042 \\
Price & Poor & -.545 & .042 \\
& Above P500 & .112 & .036 \\
& P300-P500 & .224 & .072 \\
Cleanliness & Less than P300 & .337 & .108 \\
& Excellent & .469 & .042 \\
& Average & .168 & .042 \\
Constant & Poor & -.637 & .042 \\
\hline \hline
\end{tabular}

As seen in Table 5, all utility values are highly significant. Hence, all the buffet restaurant attributes are looked upon as the basis for the selection of a buffet restaurant. The Pearson's $R$ and Kendall's tau correlations both showed significance at .01 level which means that this model re- presents the buffet restaurant attributes identified by the respondents. The correlation for holdouts indicates the model is fit, at .05 level of significance. 
TABLE 5 . Overall conjoint correlations results between observed and estimated preferences of buffet restaurant consumers based on current position

\begin{tabular}{lll}
\hline \hline Correlations & Value & Sig. \\
\hline Pearson's $R$ & .984 & $.000^{* *}$ \\
Kendall's tau & .954 & $.000^{* *}$ \\
Kendall's tau for Holdouts & .905 & $.002^{*}$ \\
\hline \hline a. Correlations between observed and estimated \\
preferences \\
*.Significant at 0.05 level of significance. \\
${ }^{* *}$.Significant at 0.01 level of significance.
\end{tabular}

As shown in Table 6, cleanliness earned the highest utility value (32.442). This is in consonance with the studies done by Fatimah et al., (2011) wherein they asserted the importance of food service hygiene or cleanliness.

Further, this aspect remains far more essential since the associated risk could be substantial. The lowest utility value was registered by Price (11.386) attribute. This means that buffet restaurant consumers no longer consider price as the primary attribute to look into in selecting a buffet restaurant. Instead, they place the highest value on the cleanliness of a buffet restaurant. Chung \& Kim (2011) clarified that price remains one of the major factors that is used in consumer decision-making as well as its subsequent behaviors. Kafel \& Sikora (2013) deepened the insight by asserting that consumers utilize price as a gauge for the quality of the restaurant. Hence, if a restaurant serves quality food, then it must be expensive.

TABLE 6. Respondents' overall average importance values on the buffet restaurant attributes based on current position

\begin{tabular}{ll}
\hline \hline Buffet Restaurant Attributes & Value \\
\hline Type of Food & 29.502 \\
Quality of Food & 28.496 \\
Price & 8.640 \\
Cleanliness & 33.362 \\
\hline \hline
\end{tabular}

As exhibited in Table 7, the overall preference (4.015) is derived from the sum of utility part-worths for each attribute plus the regression constant term. The high preference score is an indication of greater desired level of attributes which then adds a lot to the overall utility of buf- fet restaurants. In particular, cleanliness was revealed to generate the largest utility value, which is indicative of the fact that most existing buffet restaurants in Davao Region look into the cleanliness as a primary attribute factor.

TABLE 7. Preference score on the overall utility estimates of factors based on the buffet restaurant attributes

\begin{tabular}{ll}
\hline \hline Attribute Factor & Utility \\
\hline Type of Food: Filipino & .236 \\
Quality of Food: Excellent & .406 \\
Price: Less than P300 & .337 \\
Cleanliness & .469 \\
Constant & 2.561 \\
Preference Score & 4.009 \\
\hline \hline
\end{tabular}

On Job Position. Table 8 presents that there is a distinction for both the Junior and Senior professionals when it comes to buffet restaurant preferences. This is evidenced by the Kendall's tau for holdouts which is measured at a .05 level of significance. The Pearson and Kendall's correlation outcomes both indicate significance at a .01 level, which is very representative of the buffet restaurant attributes identified for both junior and senior professionals.

TABLE 8. Conjoint correlations results between observed and estimated preferences of buffet restaurant consumers when compared between junior and senior professionals

\begin{tabular}{lllll}
\hline \hline & \multicolumn{2}{c}{ Junior Professional } & \multicolumn{2}{l}{ Senior Professional } \\
\cline { 2 - 5 } & Value & Sig. & Value & Sig. \\
\hline Pearson's $R$ & .982 & $.000^{* *}$ & .973 & $.000^{* *}$ \\
Kendall's tau & .940 & $.000^{* *}$ & .920 & $.000^{* *}$ \\
Kendall's tau for holdouts & .810 & $.005^{*}$ & .905 & $.002^{*}$ \\
\hline a. Correlations between observed and estimated preferences \\
*.Significant at 0.05 level of significance. \\
**.Significant at 0.01 level of significance.
\end{tabular}

In Table 9, a clear distinction between Junior and Senior Professionals can be seen through the average importance values on the buffet restaurant attributes. A senior professional places high preference on the type of food. As regards the quality of food, a junior professional puts more regard compared to a senior professional. On the other hand, a senior professional is less price-conscious than a junior professional. When it comes to cleanliness, a senior professional places more importance than a junior professional. 
TABLE 9. Conjoint correlations results between observed and estimated preferences of buffet restaurant consumers when compared between junior and senior professionals

\begin{tabular}{lll}
\hline \hline & Junior Professional & Senior Professional \\
\hline Type of Food & 16.587 & 21.328 \\
Quality of Food & 35.172 & 29.062 \\
Price & 8.127 & 6.998 \\
Cleanliness & 40.115 & 42.612 \\
\hline \hline
\end{tabular}

The responses of the junior and senior professionals towards the attribute factors can be seen in Table 10. The junior professionals place the highest preference on a buffet restaurant that would offer Filipino type of food $(\beta=.229)$ with excellent quality $(\beta=.427)$ and is priced less than P300 $(\beta=.125)$ with excellent cleanliness $(\beta=.492)$. On the other hand, the senior professionals show a preference for a buffet restaurant that offers Filipino type of food $(\beta=.291)$ with excellent quality $(\beta=.300)$, priced at less than $\mathrm{P} 300(\beta=$ $.079)$ with excellent cleanliness $(\beta=.418)$.

TABLE 10 . Respondents' utility estimates of factors based on the buffet restaurant attributes when compared according to junior and senior professionals

\begin{tabular}{llllll}
\hline \hline \multirow{2}{*}{ Attribute } & Factor & \multicolumn{2}{l}{ Junior Professional } & \multicolumn{2}{l}{ Senior Professional } \\
\cline { 3 - 6 } & & Utility-Estimate & Std. Error & Utility-Estimate & Std. Error \\
\hline Type of Food & Filipino & .229 & .065 & .291 & .069 \\
& Korean & -.245 & .065 & -.199 & .069 \\
& Japanese & .066 & .065 & -.048 & .069 \\
& Chinese & -.048 & .086 & .008 & .090 \\
& European & -.207 & .086 & -.220 & .090 \\
Quality of Food & American & .205 & .086 & .168 & .090 \\
& Excellent & .427 & .045 & .300 & .048 \\
& Average & .151 & .045 & .097 & .048 \\
Price & Poor & -.578 & .045 & -.397 & .048 \\
& Above P500 & .116 & .039 & .084 & .041 \\
& P300-P500 & .232 & .079 & .168 & .083 \\
Cleanliness & Less than P300 & .348 & .118 & .252 & .124 \\
& Excellent & .492 & .045 & .418 & .048 \\
& Average & .161 & .045 & .184 & .048 \\
& Poor & -.654 & .045 & -.603 & .048 \\
& Constant & 2.533 & .086 & 2.651 & .090 \\
\hline \hline
\end{tabular}

In Table 11, the total utility for junior (4.029) and senior (3.912) professionals suggests that the predetermined buffet restaurant attributes for junior professionals have a much higher overall preference score over the senior professionals. Moreover, the senior professionals tend to favor more the type of food than the junior professionals. This is in conjunction with the study of Reynolds \& Hwang (2006) wherein they stressed that older consumers tend to veer away from exotic foods and newer food trends. Hence, if these consumers have been so entrenched in selecting a restaurant that offers Filipino foods, then these acquired tastes and dining pattern will be carried forward as consumer ages (Reynolds \& Hwang, 2006).

On the other hand, the junior professionals tend to prefer more excellent quality of food and cleanliness than the senior professionals. This is consistent with the findings of Soriano (2002) where in the 31-40 year old respondents affirmed more importance in the quality of food than any other restaurant attribute. Interestingly, the junior professionals tend to be more price-conscious than the senior 
professionals. Pucciarelli \& Thomas (2011) underscored that as consumers expand careers and combine incomes, purchasing power for food becomes greater, thus increasing foods bought from all food categories.

As regards cleanliness, the junior professionals place higher preference than the senior professionals. This is sup- ported by Al-Khatib \& Al-Mitwalli (2009), who underlined that safe handling of food in restaurants is a fundamental component in the reduction of foodborne diseases, which also was emphasized by one of the Focused Group Discussion participants as far as it being important in securing and retaining a job.

TABLE 11. Preference score on the utility estimates of factors based on the buffet restaurant attributes when grouped according to position

\begin{tabular}{lll}
\hline \hline Attribute Factors & \multicolumn{2}{l}{ Utility Estimates } \\
\cline { 2 - 3 } & Junior Professional & Senior Professional \\
\hline Type of Food: Filipino & .229 & .291 \\
Quality of Food: Excellent & .427 & .300 \\
Price: Less than P300 & .348 & .252 \\
Cleanliness: Excellent & .492 & .418 \\
Constant & 2.533 & 2.651 \\
Preference Score & 4.029 & 3.912 \\
\hline \hline
\end{tabular}

Conjoint analysis as a statistical tool can be used for segmentation. However, for it to create more meaning, it has to be complemented with cluster analysis. This exploratory tool procedure is intended to expose natural groupings or clusters within a dataset that would otherwise not be evident. This procedure employs an algorithm that possesses several desirable features that distinguish it from traditional clustering techniques. Further, with this method, it gives the user the ability to determine the appropriate number of clusters, and then proceed with classifying through the use of a nonhierarchical routine (Facca \& Allen, 2011).

Clusters, therefore, can be created based on both categorical and continuous variables using this tool. Also, the number of clusters are automatically selected as well as it can analyze large data files efficiently.

Figure 2 is a model summary view which presents a snapshot of the cluster model, including a Silhouette measure of cluster cohesion and separation which can be seen shaded to indicate results which are poor, fair or good. According to Kaufman \& Rousseeuw (1990), a cluster structure that has a reasonable or strong evidence will manifest a good result while fair result shows weak evidence and the poor result signifies no significant evidence. As presented, a poor silhouette measure of cohesion and separation was derived through the Two-Step clustering algorithm and forty (40) predictors. Nonetheless, it resulted into three cluster solutions. To produce a better result, one can always go back to the modeling node to amend the cluster model settings. However, in spite of several tries, the result still shows poor fit.
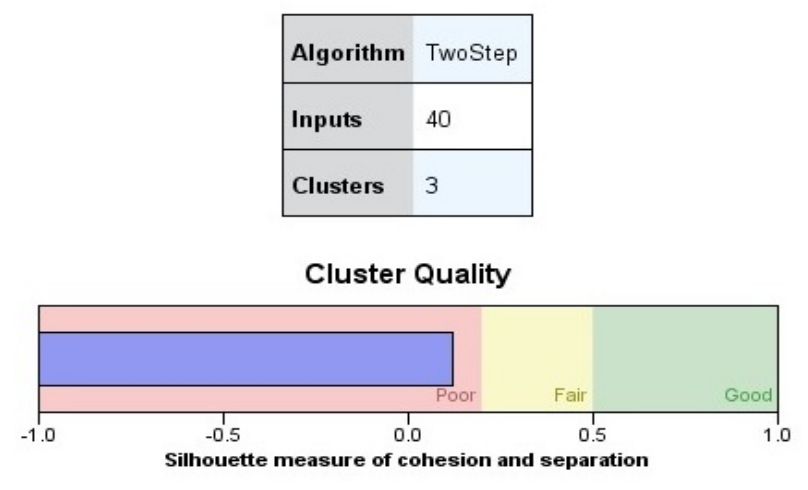

FIGURE 2 . Model summary view

The two-step cluster analysis is superior to the traditional clustering techniques since its algorithm can deal with both categorical and continuous variables, automatically determines the optimal number of clusters, and allows the analysis of large data files. With its auto-clustering function, the largest ratio of distances generated from the dataset signifies the optimal number of clusters. This automated cluster selection can be done in two ways: Bayesian Information Criterion (BIC) or Akaike's Information Criterion (AIC).

According to Jones (2011), the BIC should be seriously considered for model selection wherein there are large sam- 
ple sizes. Further, he affirmed that small changes that are too trivial to be of practical importance might be significant. Hence, the BIC holds a higher penalty for overfitting compared with AIC. However, both clustering algorithms were presented. Table 12 presents the frequency of each cluster.
Of the 500 total cases, 103 were excluded from the analysis due to missing values on one or more of the variables. Of the 397 cases assigned to clusters, 131 were assigned to the first cluster, 144 to the second, and 122 to the third.

TABLE 12. Cluster distribution

\begin{tabular}{llll}
\hline \hline Cluster & $\boldsymbol{N}$ & \% of Combined & \% of Total \\
\hline 1 & 131 & $33.0 \%$ & $26.2 \%$ \\
2 & 144 & $36.3 \%$ & $28.8 \%$ \\
3 & 122 & $30.7 \%$ & $24.4 \%$ \\
Combined & 397 & $100.0 \%$ & $79.4 \%$ \\
Excluded cases & 103 & & $20.6 \%$ \\
Total & 500 & & $100 \%$ \\
\hline \hline
\end{tabular}

Figure 3 shows the cluster predictor importance view. With this, the relative importance of each predictor in estimating the model is shown. The most important predictor has to generate 1.0. In this study, current position registered 1.0. This is closely followed by age (0.96). The buffet restaurant profile 25 (Chinese type of food, excellent quality of food, P300-P500, excellent cleanliness) came in next which showed 0.61 . This was followed by civil status $(0.56)$. Buffet restaurant profiles 30 (Chinese type of food, excellent quality of food, less than P300, excellent cleanliness), 7 (Japanese type of food, excellent quality of food, less than P300, average cleanliness), and 28 (Korean type of food, excellent quality of food, above P500, Excellent cleanliness) trailed the predictor importance.

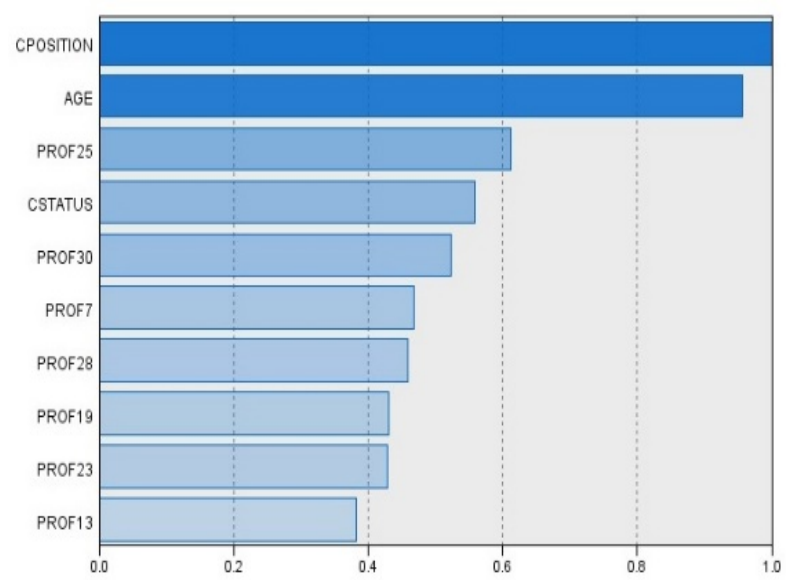

FIGURE 3. Predictor importance

The clusters view is another output of the cluster technique which contains a cluster-by-features grid composed of cluster names, profiles, sizes, and other pertinent vari ables for each cluster. Hence, from the dataset, three clus ters were labeled and described based on the significant categorical and continuous variables as seen in Figure 4.

\begin{tabular}{|c|c|c|c|}
\hline Cluster & 1 & 2 & 3 \\
\hline Label & $\begin{array}{c}\text { Single, Junior } \\
\text { Oriental Food Lover }\end{array}$ & $\begin{array}{l}\text { Mamied, Junior } \\
\text { Oriental Food Lover }\end{array}$ & $\begin{array}{c}\text { Married, Senior } \\
\text { Oriental Food Lover }\end{array}$ \\
\hline Description & $\begin{array}{c}\text { Junior Professional, } \\
31-40 \text { years old, } \\
\text { Single who likes } \\
\text { Chinese, Japanese, } \\
\text { Korean foods with } \\
\text { exeellent qualiy of } \\
\text { food and cleanliness } \\
\text { regardless of the } \\
\text { price }\end{array}$ & $\begin{array}{c}\text { Junior Professional, } \\
31-40 \text { years old, } \\
\text { Married Who likes } \\
\text { Chinese, Japanese, } \\
\text { Korean foods with } \\
\text { excellent quality of } \\
\text { food and cleanliness } \\
\text { regardless of the } \\
\text { price }\end{array}$ & $\begin{array}{l}\text { Senior Professional, } \\
41-50 \text { years old, } \\
\text { Uarried Who likes } \\
\text { Chinese, Japanese, } \\
\text { Korean foods with } \\
\text { excellent quality of } \\
\text { food and cleanliness } \\
\text { regardless of the } \\
\text { price }\end{array}$ \\
\hline Size & $\begin{array}{r}33.0 \% \\
(131)\end{array}$ & $\begin{array}{l}36.3 \% \\
(144)\end{array}$ & $\frac{30.7 \%}{(122)}$ \\
\hline
\end{tabular}

FIGURE 4. Cluster

\section{Analysis and Interpretation of Results}

Based on the outcomes presented, it is hereby posited that the present buffet restaurant consumers in Davao Region would look up to cleanliness ("Excellent"; $\beta=.469$ ) as the primary attribute factor in selecting a buffet restaurant. This is followed by quality of food ("Excellent"; $\beta=.406$ ), price ("Less than P300"; $\beta=.337$ ), and type of food ("Filipino"; $\beta=.236)$. With the total utility estimate $(y k=4.009)$, the researcher came up with a general conjoint model below:

Total Utility = Utility (Excellent cleanliness $)+$ Utility $($ Excellent quality of food) + Utility (Less than P300) + Utility (Filipino Food) + Constant

$=.469+.406+.337+.236+2.561$

$=4.009$ 
This means that the people in Davao Region find a buffet restaurant more attractive if it possesses the bundled attributes (excellent cleanliness, excellent quality of food, less than P300, Filipino food). With these bundled attributes. these people will be more inclined to avail more frequently a buffet restaurant service. Moreover, Table 13 confirms this. The simulation card number 4 has a preference score of 4.009 and a maximum utility of $59.4 \%$. As can be seen, simulation 4 earns the highest BTL, $19.0 \%$ and Logit, 29.7\%. 133 out of 144 subjects were used in the BTL and Logit methods because the subjects have all nonnegative scores. On one hand, the least preferred bundle of attributes is that of poor cleanliness, poor quality of food, Korean type of food, and above P500 price. This combination would generate total utility of:

Total Utility = Utility (Poor cleanliness) + Utility (Poor qual- ity of food) + Utility (Korean type of food) + Utility (Above P500) + Constant

$$
\begin{aligned}
& =-.673+-.545+-.221+.112+2.561 \\
& =1.234
\end{aligned}
$$

TABLE 13. Preference scores of

\begin{tabular}{lcc}
\multicolumn{3}{c}{ simulations } \\
\hline \hline Card Number & ID & Score \\
\hline 1 & 1 & 1.269 \\
2 & 2 & 2.639 \\
3 & 3 & 3.320 \\
4 & 4 & 4.009 \\
5 & 5 & 1.962 \\
6 & 6 & 3.287 \\
7 & 7 & 3.741 \\
\hline \hline
\end{tabular}

TABLE 14 . Preference probabilities of simulations

\begin{tabular}{lcccc}
\hline \hline Card Number & ID & Maximum Utility & Bradley-Terry-Luce & Logit \\
\hline 1 & 1 & $0.7 \%$ & $7.3 \%$ & $4.0 \%$ \\
2 & 2 & $5.8 \%$ & $13.3 \%$ & $9.4 \%$ \\
3 & 3 & $6.8 \%$ & $15.9 \%$ & $15.0 \%$ \\
4 & 4 & $57.3 \%$ & $19.5 \%$ & $28.7 \%$ \\
5 & 5 & $2.8 \%$ & $9.8 \%$ & $5.8 \%$ \\
6 & 6 & $11.7 \%$ & $15.8 \%$ & $14.8 \%$ \\
7 & 7 & $14.9 \%$ & $18.3 \%$ & $22.3 \%$ \\
\hline \hline
\end{tabular}

TABLE 15. Simulation cases

\begin{tabular}{lcccc}
\hline \hline Simulation & Type of Food & Quality of Food & Price & Cleanliness \\
\hline 1 & Korean & Poor & Above P500 & Poor \\
2 & Japanese & Poor & Above P500 & Excellent \\
3 & Chinese & Excellent & P300-P500 & Average \\
4 & Filipino & Excellent & Less than P500 & Excellent \\
5 & European & Average & Above P500 & Poor \\
6 & American & Average & P300-P500 & Average \\
7 & Filipino & Average & Less than P300 & Excellent \\
\hline \hline
\end{tabular}

The simulations were conducted to understand how the set of respondents would choose among specified set of profiles shown in Table 15. For junior professionals, their most preferred attribute factor is cleanliness ("Excellent"; $\beta=.492$ ). This is followed by quality of food ("Excellent"; $\beta$ $=.427$ ), price ("less than P300"; $\beta=.348$ ), and type of food ("Filipino"; $\beta=.229$ ). With the total utility estimate $(y k=$ 4.029), the researcher came up with a conjoint model for junior professionals as shown below:
Total Utility (Junior) = Utility (Excellent cleanliness) + Utility (Excellent quality of Food) + Utility (Less than P300) + Utility (Filipino Food) + Constant

$=.492+.427+.348+.229+2.533$

$=4.029$

For senior professionals, their most preferred attribute is cleanliness ("Excellent"; $\beta=.418$ ). This is followed by quality of food ("Excellent"; $\beta=.300$ ), type of food ("Filipino"; $\beta=.291$ ), and price ("Less than P300"; $\beta=.252$ ). 
With the total utility estimate $(y k=3.912)$, the researcher came up with a conjoint model for senior professionals as shown below:

Total Utility (Senior) = Utility (Excellent cleanliness) + Utility (Excellent quality of Food) + Utility (Filipino Food) + Utility (Less than P300) + Constant

$=.418+.300+.291+.252+2.651$

$=3.912$

In sum, having a greater preference score over the senior professionals means that the junior professionals are more inclined to favor the four identified buffet restaurant attributes. Cluster Analysis Based on the outcomes, the cluster analysis yields three uniquely profiled clusters. The first cluster (Single Junior Professional Oriental food lovers) is comprised of junior professionals, 31-40 years old, single. The second cluster (Married Junior Professional Oriental food lovers) is composed of junior professionals, 31-40 years old, married. The third cluster (Married Senior Professional Oriental food lovers), on the other hand, is made up of senior professionals, 41-50 years old, married. All clusters share the same preference for a buffet restaurant that offers Oriental (Chinese, Japanese, Korean) foods with excellent quality and excellent cleanliness regardless of the price.

\section{CONCLUSION AND RECOMMENDATIONS}

Given the results of the study, the researcher concludes that the order of priority as regards the four attributes (Cleanliness, Quality of Food, Type of Food, and Price) of both junior and senior professionals is the same. However, the utility values differ. For junior professionals, the utility values of each attribute are as follows: Cleanliness: excellent - .492, Quality of Food: excellent - .427, Type of Food: Filipino - .229, and Price: less than P300 -.348 while for senior professionals, the utility values of each attribute are as follows: Cleanliness: excellent - .418, Quality of food: excellent - .300, Type of Food: Filipino - .291, and price: less than P300 -.252. For junior professionals, the relative importance of each attribute is as follows: Type of food - 16.587, quality of food -35.172 , price -8.127 , cleanliness -40.115 while for senior professionals, the relative importance of each attribute is as follows: Type of food -
21.328 , quality of food -29.062 , price -6.998 , cleanliness - 42.612. Three clusters of buffet restaurant consumers in Davao Region were revealed and these clusters share the same preference for Oriental foods (Chinese, Japanese, and Korean). The first cluster (33.0\%) is comprised of junior professionals who are single and are in the age bracket of 31-40 years old. The second cluster $(36.3 \%)$ is composed of married, 31-40-year-old junior professionals. The third cluster (30.7\%), on the other hand, is primarily made up of senior professionals who are married and are in the age bracket of 41-50. Based on these conclusions, the researcher recommends that buffet restaurant owners and managers should develop a design that fits the preferences of the junior professionals and senior professionals. The buffet restaurant owners and managers, when targeting junior professionals, should also put considerable efforts to establish cleanliness standards in the premises of the buffet restaurant. Further, creating and nurturing an array of excellent quality foods should be a priority; when targeting senior professionals, owners and managers of a buffet restaurant should give more focus on cleanliness. Along with this, the quality of food, as well as the type of food, should be prioritized; the utility value of the type of food came close to the quality of food. Therefore, for senior professionals, the spirit of adventurism in trying out foreign dishes is minimal. Thus, Filipino type of food should be prioritized. Moreover, the buffet restaurant owners and managers targeting junior professionals should place much importance on cleanliness since it is their utmost consideration in buffet restaurant selection. The owners should invest in getting sanitation certifications as these would streamline hygienic processes and procedures in the organization. The owners and managers of buffet restaurant targeting senior professionals should consider cleanliness as its priority. This means that the buffet restaurants should invest in the establishment of processes that would elevate its sanitation and hygiene standards. Lastly, the owners and managers of buffet restaurants should study the needs and unique characteristics of the identified clusters so that right positioning strategies could be crafted.

\section{REFERENCES}

Ajzen, I., \& Fishbein, M. 1980. Understanding attitudes and predicting social behavior. Englewood Cliffs, NJ: Prentice- $\quad$ Hall. Akbar, Y., \& Alaudeen, M. 2012. Determinant of factors that influence consumer in chooising normal full-rervice restaurant:

Case in seri iskandar, perak. South East Asian Journal of Contemporary Business, Economics and Law, 1(4): 137-145.

Akinyele, S. 2010. Customer satisfaction and service quality: Customer's re-patronage perspectives. Global Iournal of ISSN: 2414-309X 
Man- $\quad$ agement \& Business Research, 10(6): 83-90.

Al-Khatib, I., \& Al-Mitwalli, S. 2009. Food sanitation practices in restaurants of Ramallah and Al-Bireh district of Palestine. Eastern Mediterranean Health Journal, 15(4): 951-958.

Bartlett, J., \& Han, F. 2007. Analysis of service quality in restaurants in China: an eastern perspective. Paper presented at the ABR (Business) Conference \& the 2007 TLC (Teaching) Conference, Oahu, HI.

Cattin, P., \& Wittink, D. 1982. Commercial use of conjoint analysis: A survey. Journal of Marketing, 46(3): 44-53.

DOI: $10.2307 / 1251701$

Chapman, C. 2013. 9 things clients get wrong about conjoint analysis. Paper presented at the conference of Sawtooth Software, Dana Point, CA.

Chung, J., \& Kim, S. 2011. Restaurant selection criteria: Understanding the roles of restaurant type and customers' socio- demographic characteristics. Global Journal of Management \& Business Research, 5(7): 70-86.

Cochran, W.G. 1963. Sampling techniques. New York, NY: Wiley Online.

Cruz, F.D. 1997. An application of conjoint analysis in the design of a coconut drink. Unpublished doctoral dissertation, University of the Philippines Diliman, Quezon, PH.

Cruz, M. 2004. Consumer preferences and market segments for 1.3-liter cars in Davao city, Philippines: An application of conjoint analysis as a predictive technique. Unpublished doctoral dissertation, De La Salle University, Manila, PH. Dilworth, J. 2000. Operations management: Providing value in goods and services. Orlando, FL: Harcourt College Pub- lisher.

Facca, T.M., \& Allen, S.J. 2011. Using cluster analysis to segment students based on self-reported emotionally intelligent leadership behaviors. Journal of Leadership Education, 10(2): 72-96. D0I: 10.12806/v10/i2/rf4

Fatimah, U.U., Boo, H., Sambasivan, M., \& Salleh, R. 2011. Foodservice hygine factor: The consumer perspective. Interna- tional Journal of Hospitality Management, 30: 38-45.

Fernandez, D.G. 2002. Chinese food in the Philippines. In D.Y. Wu \& S.C. Cheung (Eds.), The globalization of Chinese food, Honolulu, HI: University of Hawai'i Press.

Foxall, G. 2010. Interpreting consumer choice. New York, NY: Routledge.

Gu, C., \& Kim, Y.J. 2002. Penalized likelihood regression: General formulation and efficient approximation. Canadian Jour-

of Statistics, 30(4): 619-628. D0I: 10.2307/3316100

Haas, T.J. 2008. Today's foodservice industry demands strong leadership. New York, NY: Business Publications.

Hair, J., Black, W., Babin, B., \& Anderson, R. 2014. Multivariate data analyis. Harlow, ESX: Peason Education Limited: Pearson New International Edition.

HRI Food Service Sector. 2015. Global agricultural information network report. Manila, PH: Philippines Food Service Hotel Restaurant Institutional.

Hu, M. 2009. Developing a core competency model of innovative culinary development. International Journal of Hospital- ity Management, 6(4): 63-87. DOI: 10.1016/j.ijhm.2009.10.024

International Markets Bureau. 2010. Market analysis report. URL: goo.gl/Wy5zXb. Last accessed on 19 June 2017.

Intan, W.S. 2016. The analysis factors of experential marketing, product quality, and customer satisfaction of motor bike as a main transportation mode in bandung-indonesia. International Journal of Business and Administrative Studies, 2(1): 6-8. DOI: 10.20469/ijbas.2.10002-1

Jones, R.H. 2011. Bayesian information criterion for longitudinal and clustered data. Statistics in Medicine, 30(25): $3050-3056$.

DOI: $10.1002 / \operatorname{sim} .4323$

Kuo, M.P., \& Chen, Y.M. 2015. A Study on the relationships among body sensory experience, customer satisfaction and

cus- $\quad$ tomer loyalty-beauty SPA center as an example. International Journal of Business \& Administrative Studies, 1(2): 61-67. DOI: 10.20469 /ijbas.10003-2

Orme, B. 2010. Getting started with conjoint analysis: Strategies for product design and pricing research. California, CA: Research Publishers.

Kafel, P., \& Sikora, T. 2013. The usage of quality management methods and tools in food. Food Science Technology Quality, 1(86): 204-216.

Kang, S., Nobuyuki, O., \& Herbert, D. 2004. Service quality and its effects on customer satisfaction and customer behavioural intention: Hotel and ryokan guests in Japan. Asian Pacific Journal of Tourism Research, 9(2): 189-203. 
Kaufmann, L., \& Rousseeuw, P.J. 1990. Finding groups in data. New York, NY: John Wiley \& Sons, Inc.

Kotler, P. 2013. Principles of marketing. Harlow, ESX: Prentice Hall.

Olsen, S. 2002. Comparative evaluation and the relationship between quality, satisfaction, and repurchase loyalty. Academy of Marketing Science, 30(3): 240-249. DOI: 10.1108/mbe.2002.26706dae.004

Patayon, E.C. 2008. Parental preferences concerning preschools. Unpublished doctoral dissertation, Ateneo de Davao Uni- versity, Davao, PH.

Pucciarelli, D., \& Thomas, A. 2011. Determinates that influence food consumption among older members of a midwest com- munity. Food and Nutrition Sciences, 2(9): 1018-1026. D0I: 10.4236/fns.2011.29136

Regional Development Council Region XI. 2011. Davao regional development plan 2011-2016. URL: goo.gl/4rR6DJ. Last accessed on 18 May 2017.

Reynolds, J.S., \& Hwang, J. 2006. Influence of age on customer dinning experience factors in US Japanese restaurants. An International Multidisciplinary Journal of Tourism, 1(2): 29-43.

Riehle, H., Grindy , B., \& Stensson, A. 2014. Restaurant industry forecast. Washintong, DC, WA: National Restaurant Asso- ciation.

Roman, B., \& Russell, S. 2009. Southeast asian food and culture. URL: goo.gl/CzYXrj. Last accessed on 20 May 2017. Slovic, P., Fischhoff, B., \& Lichtenstein, S. 1977. Behavioural decision theory. Annual Review of Psychology, 28(1): 1-39. Soderlund, M., \& Ohman, N. 2005. Assessing behaviour before it becomes behaviour: An examination of the role of intenas a link between satisfaction and repatronising behaviour. International Journal of Service Industry Manage- ment, 16(2): 169-185. DOI: 10.1108/09564230510592298

Soriano, R. 2002. Customers' expectations factors in restaurants: The situation in Spain. The International Journal of Quality \& Reliability Management, 19(8/9): 1055-1067.

Saputra, R., \& Dewi, C.K. 2016. The impact of brand trust on brand loyalty mediated by customer satisfaction: Case of Tokoba- gus.com (now OLX.co.id). Journal of Administrative \& Business Studies, 1(1): 8-13. D0I: 10.20474/jabs-1.1.2 Temblor, S.B. 2016. News section. URL: goo.gl/u2hBnQ. Last accessed on 18 June 2017.

Waldfogel, J. 2008. The median voter and the median consumer: Local private goods and population composition. Journal of Urban Economics, 63(2): 567-582. DOI: 10.3386/w11972

- This article does not have any appendix. - 